\title{
IoT Based Health Monitoring System
}

\author{
Jayakumar $\mathrm{S}^{\mathrm{a}, 1}$, Ranjith kumar $\mathrm{R}^{\mathrm{b}}$, Tejswini $\mathrm{R}^{\mathrm{b}}$ and Kavil $\mathrm{S}^{\mathrm{b}}$ \\ ${ }^{a}$ Assistant Professor (S.G), Department of Electronics and Instrumentation \\ Engineering, KCG college of technology, Chennai \\ ${ }^{\mathrm{b}}$ Students, Department of Electronics and Instrumentation Engineering, KCG college of \\ technology, Chennai
}

\begin{abstract}
Normally, a health issue or an emergency needs to viewed in a multidisciplinary approach. And, thus a standard sensor-based diagnosis in the medical field, requires a greater number of sensors and human efforts if it's processed on a large scale. To overcome this issue an IoT-based health care application is proposed in this research work. The proposed system consists of an online mobile application that supports continuous wireless monitoring of patients. The Main aim of the paper is to implement a low-cost system and send the patient vital parameters in case of emergency situations. Sensors such as ECG Monitor sensor, Heart Rate sensor, and temperature sensor are used to quantify the patient vital signs. The sensor data are collected and transferred to the cloud for storage of the IoT platform via a module which is connected to the micro controller. The information is processed within the cloud and the appropriate feedback steps are taken on the analyzed data which may be further analyzed by a doctor remotely in person. Remote viewing reduces the burden to doctors and also provides the precise health status of patients. If the patient needs urgent attention, then a message alerts is sent to the care taker or doctor. This kind of mechanism helps in taking precautions beforehand and also helps the doctor to analyze the patient in a better way. The setup is verified using simulation and various test experiments.
\end{abstract}

Keywords. Health care system, IoT, sensors, IoT platform, Arduino.

\section{Introduction}

In the rural areas, as of our survey, there's a scarcity of proper health treatments for the people, and that they don't find the proper quality of treatment. Widely, people get the treatment after the disease has affected their body to the where it gets very critical. Meanwhile, while considering the value of treatment also many of the agricultural people, mostly farmers cannot afford it.

Thus, to act as a much easier treatment process, we have designed our project in a minimalistic form but much more effective. This project is meant to offer a major parameter to diagnose the disease. The Internet of Things (IoT) is rapidly growing attention not only in certain fields but much more, especially in personalized healthcare [1-5]. Medical scientists and researchers, work hard within the field of innovation and research for many decades to urge better health services and happiness in human lives [6,7]. The

\footnotetext{
${ }^{1}$ Jaykumar S, Department of EIE, KCG college of technology, Chennai, India.

E-mail: jayakumar.ei@kcgcollege.com.
} 
blood heat, pulse, vital signs, respiration rate are the most vital parameters to diagnose a disease. This project gives temperature and pulse values using sensors and these data can be viewed efficiently with the help of the IoT platform-ThingSpeak.

\section{Literature Survey}

The literature review of the paper that were referenced and those that serves the base paper and supporting paper which provides the clear idea of the healthcare system and machine learning algorithms and proper method of recommendations.

Shoban Babu et al. [8] has put forward a concept where a patient's health is monitored efficiently with the help of IoT. It is primarily used to discover a patient's disorder and it provides a suitable remedy for the recovery of patient's health. IoT also helps in alarming the peers in the event of sensing an abnormality by the help of various sensors setup.

Sreekanth et al. [9] discuss on collection and transferring of a data in the cloud. The sensed data is then processed by the microcontroller however there is no proper method to send the data or to classify the data according to the patients.

Wan et al. [10] has designed the IoT Based Patient Health Monitoring System. In this, the wireless sensors from different parts of the body are interlinked to the node and then connected to the server. But the downside of this work is that the sensors are wireless and the data derived across the sensors can be uncertain.

Valsalan P et al. [11] used only Arduino to operate the data which collects data across the sensors and these are stored and then transferred to the database to access them for future purpose. They didn't create a EMR profile for patients, which is used to record the patient's information that can be easily accessed by anyone.

Yeri $\mathrm{V}$ et al. [12] proposed an idea about monitoring the body condition of the patients from anywhere in the world. But they didn't use RFID tag for the sensors to collects the patient's body information in a particular manner. The main drawback is that the data across the sensors which is transferred to the database is not proper and it's difficult to access them at any instant of time and lack of documentation.

\section{Methodology}

The Table 1 show the hardware components used to develop a device. In this Arduino UNO is the microprocessor, Max30100, Ec0567, Ad8232 are the sensor that are connected in the human body. The LCD used for the display

\subsection{Hardware parts}

\subsubsection{Esp8266 Module}

The development board consisting of the ESP-12E module is incorporated with the ESP8266 chip having 32-bit LX106 RISC microprocessor. The Board operates at a clock frequency of $80 \mathrm{MHz}$ to $160 \mathrm{MHz}$. Most of the IoT projects commonly use the NodeMCU module which is capable of storing data and programs in its $4 \mathrm{MB}$ flash memory. NodeMCU is powered through a micro-USB inlet and has inbuilt Wi-Fi support. It supports UART, SPI, and I2C interface. 


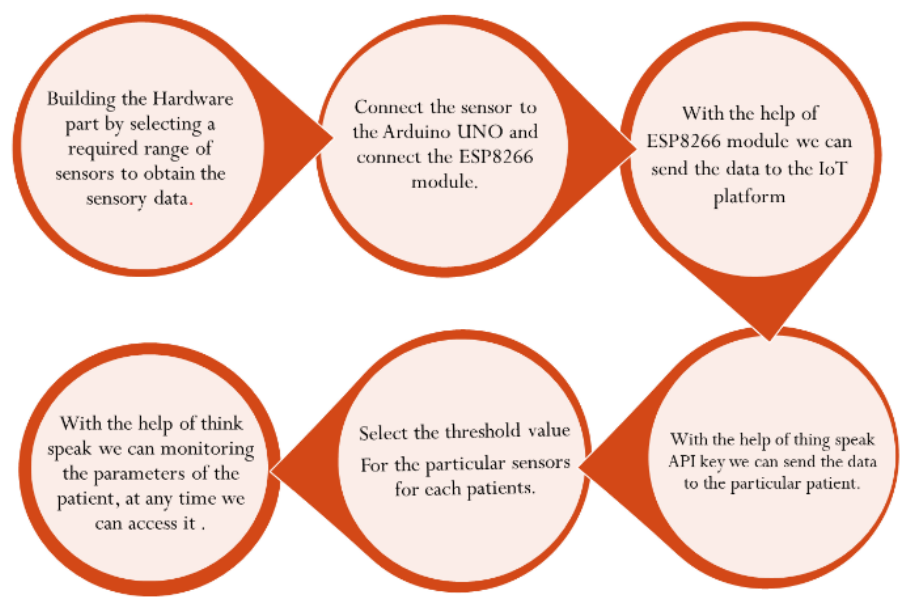

Figure 1. Methodology of the system

Table 1. Hardware Components Description

\begin{tabular}{|l|l|l|}
\hline $\begin{array}{c}\text { S. } \\
\text { No }\end{array}$ & Name of the components & Description \\
\hline 1 & ESP8266 & Send data to the MySQL Database through Wi-Fi module. \\
\hline 2 & MAX30100 Pulse oximeter sensor & Sensor used to sense the blood oxygen level in body. \\
\hline 3 & Arduino UNO R3 & $\begin{array}{l}\text { This microcontroller board is used to Reads the data from the } \\
\text { sensors. }\end{array}$ \\
\hline 4 & EC-0567 heart sensor & Detects the heart rate of the human body. \\
\hline 5 & AD-8232 ECG Monitor sensor & $\begin{array}{l}\text { Sense the pulse rate and gives the ouput is in the waveform } \\
\text { (ECG wave) }\end{array}$ \\
\hline 6 & LM35 & Sensor used to measure the body temperature. \\
\hline 7 & Thing speak & It stores and retrive the data sensed by the sensors. \\
\hline
\end{tabular}

\subsubsection{Arduino Uno}

It is one of the most commonly used microcontroller boards named ATmega328P. This UNO board consists of 14 digital Input and output pins, 6 analog inputs, one USB connection, a single power channel, and a reset button. The Arduino board can be powered via USB cable by connecting to the computer or by using an AC-to-DC adapter.

\subsubsection{Heart Rate Sensor}

The heart sensor measures pulse rate, which is the changes in the volume of a blood vessel that occurs when the heart pumps the blood. The heart rate sensor is reliable. The live heart rate data can be viewed on the display. Pulse Sensor has an inbuilt amplification and noise cancellation circuit in the hardware. The data can be read faster and easier. Pulse Sensor works on either a $3 \mathrm{~V}$ or 5V DC power supply. It can be plugged straight into a NodeMCU or a Breadboard.

\subsubsection{ECG Monitor Sensor}

It is integrated by a single chip which is specially designed for extraction, amplification, and filtering the bipotential signals. It consists of three leads that act as an operational 


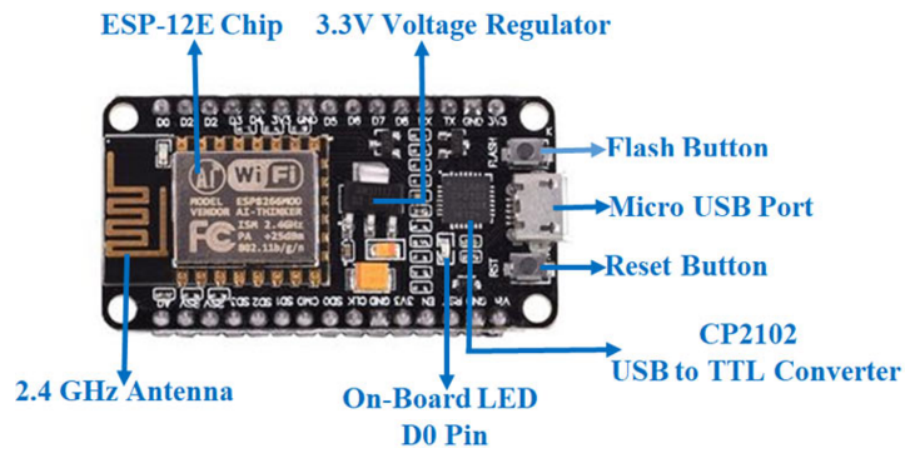

Figure 2. ESP8266

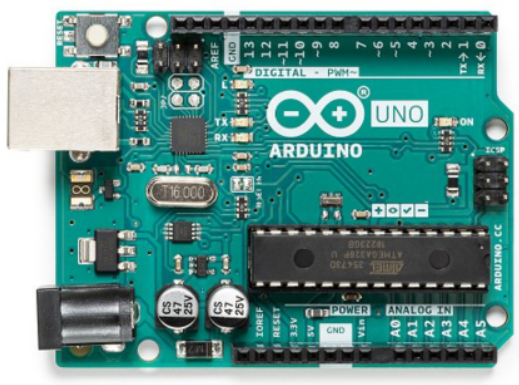

Figure 3. Arduino UNO

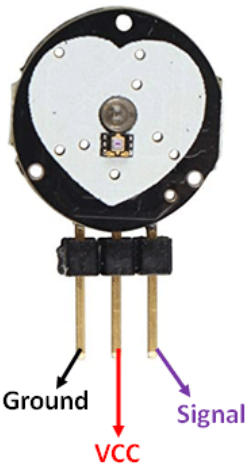

Figure 4. Hear rate sensor

amplifier to get a clear signal. The ECG signals obtained from the patient contain more noise at the output side. In order, to overcome this issue an operational amplifier is used in the module which helps in obtaining a clear output signal.

\subsubsection{LM 35 Temperature Sensor}

A temperature sensor is used to detect the body temperature. It can measure the temperature in the range of -55 degrees centigrade to 150-degree centigrade. The accuracy range of the temperature sensor is high when operated at optimal temperature and humidity level. The input voltage on the sensor varies from $4 \mathrm{v}$ to $30 \mathrm{v}$ and also consumes a current of 50Ma.

\subsubsection{Thing Speak (IoT Platform)}

It is an open IoT platform used to transfer data from any Internet-enabled device to the cloud. By configuring various actions and alerts it supports your real-time data and unlocks your data using visual tools. Think speak helps the developers to a great extent by capturing the sensor data and convert it into useful information. Thing Speak server is an open service that is free of cost and helps the development of the small noncommercial project. 


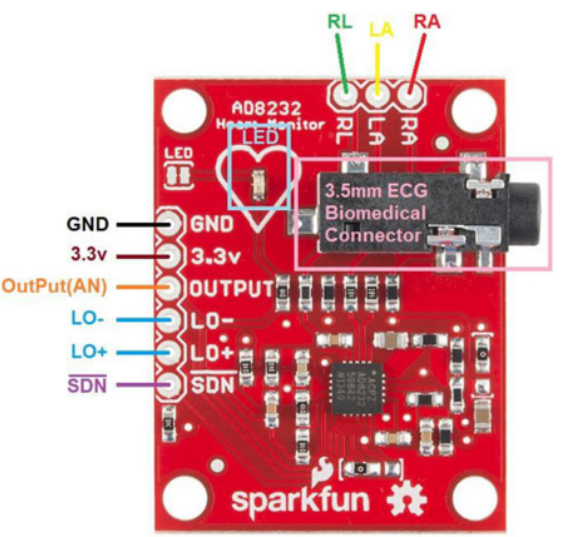

Figure 5. ECG monitor sensor

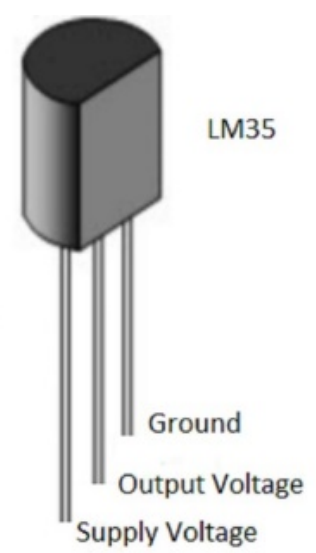

Figure 6. Pulse oximeter

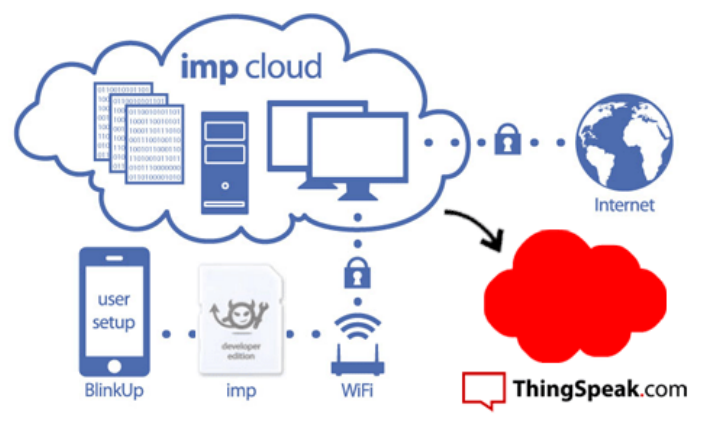

Figure 7. Overview of ThingSpeak

\section{Architecture of the Health Monitoring system}

In this system, the sensors are collecting the health data from the patients for data acquisition. Communications in the hardware part can be done by Arduino UNO and ESP8266 module for sending data to the server. The ThingSpeak server can be identified with the help of an API key. Data processing is done at the ThingSpeak server. the sensed data are stored in the database of the ThingSpeak. If patients want to know their health-related information's was shown on the web page of the Thing speak. Here Thing speak plays and Arduino UNO plays the major role. Because the Arduino collects the data from each sensor. And transfer to the thing speak IoT platform. With the use of an API key, we can transfer the data to the specified space in the cloud. Here we can access these data at times and also documentation available. We can download the data in .CSV format. But in the free version, we can only access some limited storage.

The hardware part shows the accurate results of the vitals of the patient as shown in above Figure 8. the sensor senses the data from the patient body. The Node MCU helps to process the data and sent it to the Thing speak cloud. If any parameter value crossed the threshold value the sensor reading is changed into red color and indicating to the doctor of an emergency situation in which the patient goes to an abnormal state which requires immediate assistance to the patient. The patient can move freely if the 


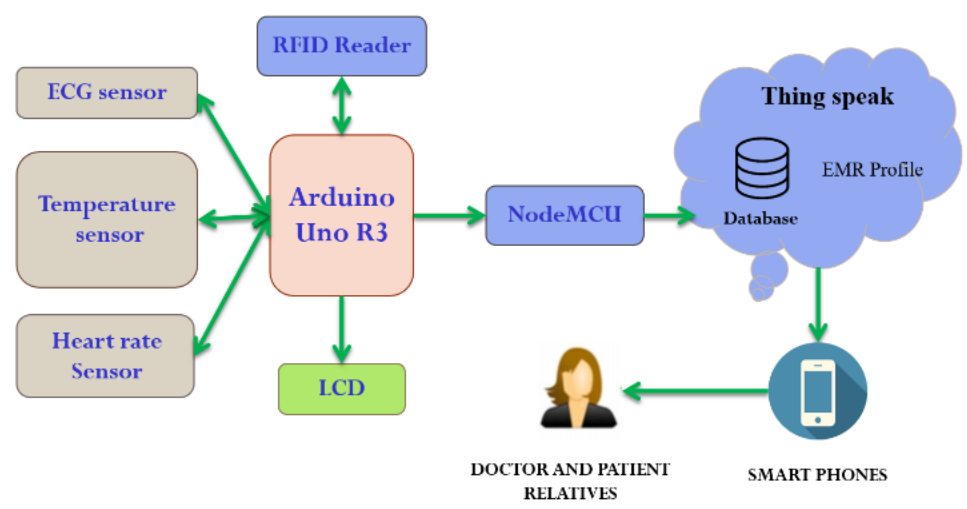

Figure 8. Block diagram

patient wants. The processor processes the data sensed by the sensors and processed data transferred to the ThingSpeak cloud through the ESP8266 module. The sensed data from the patient body can be seen on the webpage using the PC or mobile. The sensors sense and transfer the data every 20seconds. if any data of the vital parameters of the patient will exceed the threshold values, then the doctor will receive an alert message. So, he will take immediate action to the patient.

\section{Results}

This hardware setup basically consists of Heart Rate sensor, ECG Monitor sensor, Temperature sensor. These sensors are used to measure and monitor the values of pulse and temperature. After the values are found out the data is sent to the micro controller. The micro controller takes the necessary action and decides on sending the data. The data is sent using a Wi-Fi Module and it is stored in ThingSpeak.

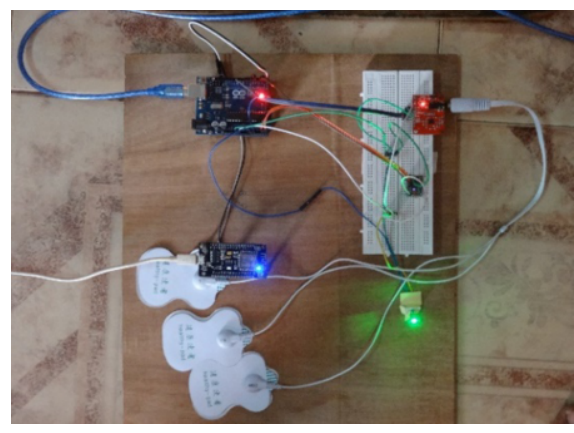

Figure 9. Hardware setup

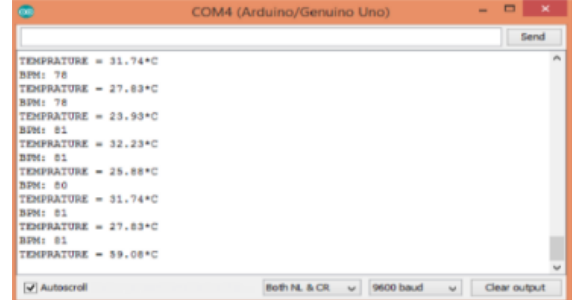

Figure 10. Simulation on Arduino IDE

In order to analyse the sensors and test our sensors we have used a software called Arduino IDE which is the only software that supports our micro controller. The above 


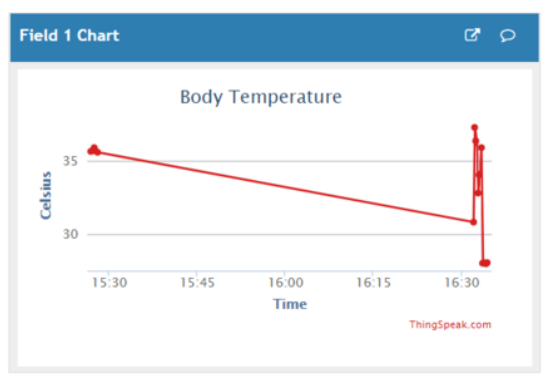

Figure 11. Graph on Temperature sensor output

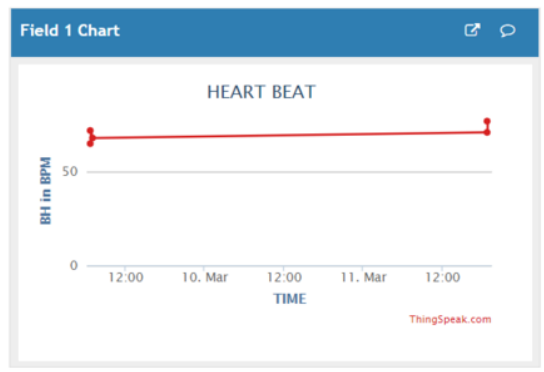

Figure 12. Graph on Heart rate sensor output

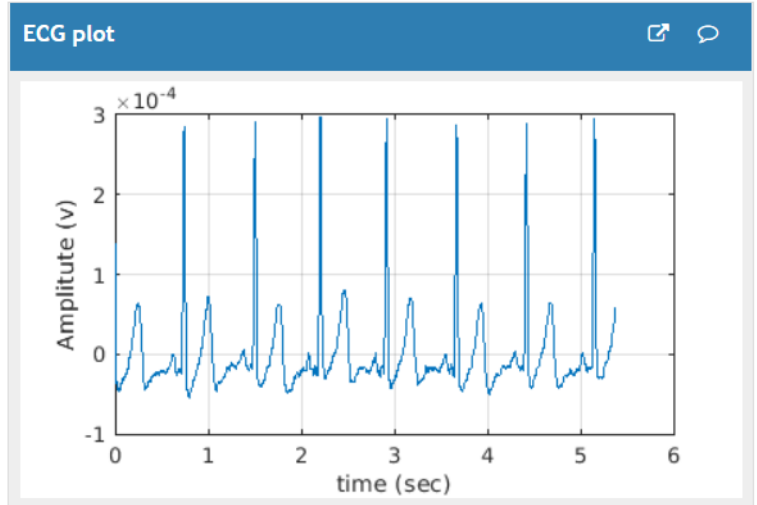

Figure 13. Graph on ECG sensor output

figure, denotes the simulations performed during testing platforms. In order to analyse the sensors and test our sensors we have used a software called Arduino IDE which is the only software that supports our micro controller. The above figure, denotes the simulations performed during testing platforms. The heart rate values are sent to the cloud platform called ThingSpeak and the values are continuously monitored and stored. The above figure depicts the fluctuations in temperature of the patient and it can be monitored by the doctor any time. The Electro Cardiogram signals are sent to the cloud platform called ThingSpeak and the values are continuously monitored and stored. The above figure depicts the fluctuations in temperature of the patient and it can be monitored by the doctor any time.

\section{Conclusion and future work}

The Human services field is always containing a huge measure of medical data, for handling those medical information certain methods are utilized. processing is one altogether method that is regularly utilized by the experts in this field. This paper focuses on the important time data for more accurate prediction using IoT. The predicted info is observed within the google sheet. Further, It will be very helpful for the villages people 
for mass screening system where hospital facilities are not available like in rural areas. In future work, we will add some additional Features like automatic and ease of Use, of The Patient Having Other Kinds of Diseases Too. In order to add machine learning is used to predict the disease and giving some helpful recommendations to the patients whether the body is in the normal state or abnormal state. To Make Use of Smaller and Light Weight Sensors in the Wearable Device in Order to Measure Number of Parameters Hence Making the Classification of Diseases More Accurate and Precise.

\section{References}

[1] Prasath JS, Ramachandraiah U, Muthukumaran G. Modified Hardware Security Algorithms for Process Industries Using Internet of Things. Journal of Applied Security Research. 2021 Jan 2;16(1):127-40.

[2] Prasath JS, Jayakumar S, Karthikeyan K. Real-Time Implementation for Secure monitoring of Wastewater Treatment Plants using Internet of Things. International Journal of Innovative Technology and Exploring Engineering. 2019;9(1):2997-3002.

[3] Selvanayakam A, Varishnee AC, Kalaivani M, Ranjithkumar G. Health Monitoring System Using IoT. InInnovations in Electrical and Electronics Engineering 2020 (pp. 739-750). Springer, Singapore.

[4] Usha Rani S, Ignatious A, Hari B, Balavishnu V. IoT patient health monitoring system. Indian Journal of Public Health Research and Development. 2017 Oct 1;8(4)1329-34.

[5] Luo Y. Environmental cost control of coal industry based on cloud computing and machine learning. Arabian Journal of Geosciences. 2021 Jun;14(12):1-6.

[6] Abarna SS, Renija D, Saffana Parveen S, Saradha Preetha S. Smart wearable health monitoring system for diagnosing diseases in patients. International Research Journal of Engineering and Technology (IRJET). 2018 Feb;5(2):178-81.

[7] Al-Aubidy KM, Derbas AM, Al-Mutairi AW. Real-time healthcare monitoring system using wireless sensor network. International Journal of Digital Signals and Smart Systems. 2017;1(1):26-42.

[8] Shoban Babu B, Srikanth K, Ramanjaneyulu T, Lakshmi Narayana I. IoT for healthcare. International Journal of Science and Research. 2016 Feb;5(2):322-6.

[9] Sreekanth KU, Nitha KP. A study on health care in Internet of Things. International journal on recent and innovation trends in computing and communication. $2016 \mathrm{Feb}$;(2):44-7.

[10] Wan J, Al-awlaqi MA, Li M, O’Grady M, Gu X, Wang J, Cao N. Wearable IoT enabled real-time health monitoring system. EURASIP Journal on Wireless Communications and Networking. 2018 Dec;2018(1):1-10.

[11] Valsalan P, Baomar TA, Baabood AH. IoT based health monitoring system. Journal of critical reviews. 2020;7(4):739-43.

[12] Yeri V, Shubhangi DC. IoT based Real Time Health Monitoring. In2020 Second International Conference on Inventive Research in Computing Applications (ICIRCA) 2020 Jul 15 (pp. 980-984). IEEE. Yeri V, Shubhangi DC. IoT based Real Time Health Monitoring. In2020 Second International Conference on Inventive Research in Computing Applications (ICIRCA) 2020 Jul 15 (pp. 980-984). IEEE. 